\title{
LA POTESTAD REGLAMENTARIA DE LAS CORPORACIONES LOCALES EN EL PROYECTO DE LEY REGULADORA DE LAS BASES DEL REGIMEN LOCAL (*)
}

352(094): 35.077 .6

por

\section{Antonio Embid Irujo}

Profesor Titular de Derecho Administrativo de la Universidad de Zaragoza

SUMARIO: I. GENERALIDADES. LOS DEFECTOS DEL SISTEMA PRECONSTITUCIONAL.-II. LA DECLARACION DE AUTONOMIA MUNICIPAL POR LA CONSTITUCION.-III. LA EVOLUCION LEGISLATIVA POSTERIOR.-IV. EL PROYECTO DE LEY REGULADORA DE BASES DEL REGIMEN LOCAL: 1. AMPLIAS REFERENCIAS A LA POTESTAD REGLAMENTARIA. 2. LA MODERNIDAD TERMINOLOGICA. 3. LAS AUTORIDADES OUE PUEDEN EMANAR REGLAMENTOS MUNICIPALES Y SU FUNDAMENTACIÓN. 4. EL PROCEDIMIENTO DE ELABORACIÓN. 5. El QUÓRUM DE APROBACIÓN. 6. LA PUBLICACIÓN DE LAS ORDENANZAS Y LA ENTRADA EN VIGOR DE SUS PRECEPTOS. 7. LOS LfMITES DE LOS REgLAMENTOS MUNICIPALES. 8. LA GENERALIZACIÓN DEL CONTROL JUDICIAL. 9. FINAL: LA NUEVA ORDENACIÓN DE LAS COMPETENCIAS MUNICIPALES.

(*) Texto de la Comunicación presentada por el autor a las Jornadas que sobre Administración local organizó la Dirección General de lo Contencioso del Estado, celebradas en Madrid durante los días 28 de mayo a 1 de junio de 1984. 


\section{GENERALIDADES. LOS DEFECTOS DEL SISTEMA PRECONSTITUCIONAL}

Cuando en 1978 publicaba mi tesis doctoral sobre las Ordenanzas municipales (1) debía, por fuerza, en las páginas finales hacer constar cómo algunas de las anomalías detectadas en el estudio se corregirían, sin duda, con la proclamación por la próxima Constitución de la autonomía municipal. En efecto, el estudio se había hecho -al margen de los planteamientos de Derecho comparado o de la amplia introducción histórica - tomando como objeto fundamental de consideración los preceptos de la Ley de Régimen local (LRL) y normativa concordante que se referían a las Ordenanzas municipales. Del exảmen de los mismos se habían podido deducir una serie de defectos que permitían poner en tela de juicio la libertad municipal en la emanación de sus Reglamentos e incluso la aplicabilidad de alguna de las características que debían acompañar a una fuente de Derecho. Entre ellos podría destacar los siguientes:

a) El fuerte intervencionismo de la Administración del Estado en el control de la potestad reglamentaria municipal. Aun cuando esta nota era menos advertible en las Ordenanzas de policía y buen gobierno (arts. 108 y sigs. de la LRL, singularmente en el 110), sin embargo, en el estudio se hacía notar cómo esta forma reglamentaria estaba, de hecho, vaciada de contenido por el surgimiento de una normativa sectorial (2) que se había ido desgajando poco a poco del tronco común mediante Leyes, o normativa de rango inferior, excepcionadoras de los principios generales del Régimen local. De esa forma, Ordenanzas sobre aprovechamientos especiales de bienes comunales, de medio ambiente, urbanísticas, etc...., conocían, de hecho y de derecho, controles de oportunidad, actos de aprobación susceptibles de llevar consigo una sustitución de los preceptos municipales, etc. Incluso hacía notar cómo era posible que normas-tipo estatales debieran ser literalmente copiadas por los Ayuntamientos, poniéndose entonces por completo en tela de juicio la libertad municipal.

b) Esta actuación estatal podría, no obstante, ser comprensi-

(1) A. Embid IRUjo: Ordenanzas y Reglamentos municipales en el Derecho español, Ed. IEAL, Madrid, 1978, 783 págs.

(2) Vid. especialmente el cap. VI de mi libro, págs. 509 y sigs. 
ble si se fundamentara en normas de rango legal o en normativa con apoyo legal. El estudio demostraba, sin embargo, que había sido usual el olvido de los estrictos principios de la relación jerárquica entre normas, de tal manera que simples Ordenes ministeriales, verdaderos Reglamentos independientes, tenían el efecto que se ha descrito en el párrafo anterior.

c) Por fin, había características, como la falta de exigencia legal de la necesidad de publicación oficial de las Ordenanzas, que eran incomprensibles si se partía, como era lógico hacerlo, y yo lo hacía, del carácter de fuente de Derecho de las Ordenanzas y Reglamentos municipales.

\section{LA DECLARACION DE AUTONOMIA MUNICIPAL POR LA CONSTITUCION}

Era evidente que podían existir varaciones si la Constitución, que se estaba elaborando cuando el libro veía la luz, contenía, por fin, la declaración de autonomía municipal que el Anteproyecto y el Proyecto contemplaban. Esa nota, que implicaba, lógicamente, la libertad de elaboración dentro del marco jurídico, afectaba al proceso de formación de la voluntad municipal, y a la misma extensión de ésta, pues también debería quedar respetado un cierto ámbito de competencias municipales (3). Por supuesto, que la misma existencia de un régimen democrático - como se ponía de manifiesto en el libro- era complemento indispensable para que existiera suficiente garantía de esa autonomía.

Como es sabido, lo que era un pronóstico y un deseo en el libro, se haría realidad en los artículos 137 y 140 de la Constitución, en los que aparecía garantizada la autonomía de los Municipios para la gestión de sus respectivos intereses.

Son estos artículos los que servirían de base para la formulación de un recurso de inconstitucionalidad contra diversos artículos de la LRL, que daría lugar a una de las primeras sentencias del Tribunal Constitucional, la 4/1981, de 2 de febrero. Es muy importante esta sentencia, desde el punto de vista del presente trabajo, tanto a los efectos de la definición de la autonomía municipal como de la

(3) Sobre el contenido de la declaración constitucional de autonomía, me remito a mi trabajo: «Autonomía municipal y Constitución: aproximación al concepto y significado de la declaración constitucional de autonomía municipal», $R E D A, 30,1981$, páginas 437 y sigs. 
aplicación de esa definición al procedimiento de control de las Ordenanzas locales.

Así, en relación a la definición de autonomía y aun cuando es ya bien conocida la doctrina del Tribunal Constitucional, no es, en este momento, de ninguna forma ocioso recordar que para el Tribunal Constitucional la autonomía es un poder limitado que exige el dotar a cada Ente de las competencias propias y exclusivas que sirvan para satisfacer el interés respectivo. En última instancia, es la Ley quien concreta el ámbito de autonomía.

Desde la perspectiva del control, la autonomía no es incompatible con el control de legalidad, sino sólo con los controles genéricos e indeterminados, por lo que implicaría de subordinación extraordinaria del controlado. Los únicos controles que podrían existir son puntuales, referidos a supuestos en los que el ejercicio de las competencias de la Entidad local incidiera en intereses generales concurrentes con los propios de la Entidad. Lo que sería incompatible con la declaración de autonomía municipal es la existencia de controles de oportunidad, a no ser que pudieran fundarse en la Constitución. En ese sentido, el principio de defensa del patrimonio de los Entes públicos, que está presente en la Constitución, puede basar un control de oportunidad siempre que sea una medida proporcionada para la defensa del patrimonio.

Toda esta doctrina se va a ir aplicando a los artículos concretos de la LRL sujetos al recurso de inconstitucionalidad. En concreto, y en relación a la potestad reglamentaria municipal, dos eran los artículos sometidos a recurso, el 110 (4) y el 723, 4, b) (5). De los controles previstos en ambos, el Tribunal Constitucional afirma su sujeción a la doctrina antes dicha con las siguientes palabras:

(4) Creo que es prudente aquí recordar el texto de un precepto que pronto será historia: «1. Dentro de los treinta días de la recepción de las Ordenanzas o Reglamentos, el Gobernador civil deberá advertir a la Corporación municipal las infracciones legales que contengan. Esta advertencia producirá los mismos efectos que la suspensión decretada, con arreglo al artículo 366 de esta Ley, por el Presidente de la Corporación, quien dará cuenta de aquélla, en plazo de cuarenta y ocho horas, al Tribunal Provincial de lo Contencioso-administrativo, el cual, en término de quince días y oído el Fiscal, revocará la suspensión o declarará la nulidad de las Ordenanzas y Reglamentos.

2. Si el Gobernador civil no hiciese ninguna advertencia de ilegalidad dentro del plazo de treinta días señalado en el párrafo anterior, las Ordenanzas y Reglamentos tendrán carácter ejecutivo».

(5) El texto controvertido indicaba que «sería» motivo legal para devengar la imposición de nuevas exacciones y la aprobación o modificación de una Ordenanza..., «b) la existencia de defectos de forma que hagan imprecisa la determinación de la base o de la obligación de contribuir». 
«El artículo 110 de la Ley de Régimen local no puede calificarse de opuesto a la Constitución. La competencia atribuida al Gobernador en relación a las Ordenanzas y Reglamentos municipales se concreta en un control de legalidad de alcance limitado, ya que la suspensión tiene carácter provisional hasta tanto decida la jurisdicción contencioso-administrativa» (fundamento jurídico 12, c).

El artículo $723,4, b$ ), de la Ley de Régimen local establece un control de legalidad en materia de imposición de nuevas exacciones y de aprobación o modificación de las Ordenanzas correspondientes. Por ello, de acuerdo con las consideraciones generales del epígrafe anterior, no puede calificarse de opuesto a la Constitución dado, además, que el poder tributario de las Corporaciones locales tiene carácter derivado, de acuerdo con el artículo 133, 1 y 2, de la Constitución".

\section{LA EVOLUCION LEGISLATIVA POSTERIOR}

La evolución legislativa posterior a esta sentencia afectó a algunas de las formas reglamentarias municipales, no obstante la declaración de la sentencia de la compatibilidad con la Constitución de las formas establecidas de control. En concreto, los artículos 18, 19 y 20 de la Ley 40/1981, de 28 de octubre, sobre régimen jurídico de las Corporaciones locales, derogan los artículos 722, 723, 725 y 726 de la LRL, suprimiendo el control del Delegado de Hacienda sobre las Ordenanzas fiscales, haciendo, por tanto, que los acuerdos municipales sirvieran para aprobar definitivamente esta forma reglamentaria local.

De menor importancia son las referencias de esta Ley en cuanto a quórums para aprobar Ordenanzas, reclamaciones contra ellas y otras, pero, en cualquier forma, dignas de ser notadas en cuanto van reformando el ordenamiento general sobre las mismas basado en la LRL (6).

No obstante, y aun con estas modificaciones, que en el caso de las Ordenanzas fiscales son cualitativamente importantes, el ordenamiento juridico de las Ordenanzas -como el mismo ordenamiento del Régimen local - seguía sin ser reformado de manera general y las adecuaciones a la Constitución eran, por tanto, puntuales. El amplio mundo de las Ordenanzas municipales necesitaba un proceso de interpretación de acuerdo con la Constitución si quería ser leído con seguridad. Hay que notar que de la misma forma en que no se

(6) Vid., por ejemplo, el artículo 3 de esta Ley en diversos párrafos, singularmente, el $2, h)$, y $2, l)$. 
produjo la reforma legislativa general, tampoco hubo estudios doctrinales de mediana calidad o de amplias perspectivas sobre esta cuestión en este período postconstitucional $\mathrm{y}$, por último, tampoco la jurisprudencia de las Salas de lo Contencioso-administrativo llevó a cabo, en las escasas ocasiones en que tuvo ocasión para ello, ese proceso de interpretación o de adecuación al ordenamiento constitucional que quizá hubiera sido preciso emprender sin dilaciones en el caso de determinadas normas reglamentarias locales. Doctrina y jurisprudencia han acompañado, por tanto, con respeto el silencio del legislador.

\section{EL PROYECTO DE LEY REGULADORA DE BASES DEL REGIMEN LOCAL}

Por eso es una buena noticia la reciente publicación del Proyecto de Ley reguladora de las Bases del Régimen local (7). Buena noticia, con independencia de las legítimas críticas que se puedan mantener respecto a su texto, por el simple hecho de que se intenta la reforma y adecuación del Régimen local y, a la vez, se tiene conciencia de que el Régimen local postconstitucional se incardina en el llamado Estado de las Autonomías, lo que implica una serie importante de mutaciones respecto a las clásicas - y monumentalesLeyes reformadoras del Régimen local. No voy a hacer, por supuesto, una lectura general del Proyecto ni tampoco en relación a las competencias de las Comunidades Autónomas, pues esta referencia se ha hecho, como es obvio, a mero título de ejemplo. Me voy a centrar exclusivamente en los preceptos, y singularmente en las novedades, que el Proyecto aporta en relación a la potestad reglamentaria municipal.

Pero antes de entrar en materia me gustaria deshacer un posible equívoco. No es, pese a su aparente modestia, el estudio de la potestad reglamentaria municipal un tema menor dentro del Régimen local, y de este Proyecto en concreto. Si así se pensara no se habría acabado de comprender el carácter de símbolo, de muestra que para todo el Régimen local tienen las Ordenanzas y Reglamentos municipales. Son, como he repetido ya, una fuente de Derecho y una manifestación de autonomía, y como tales manifestaciones de auto-

(7) Se publica en el Boletín Oficial de las Cortes-Congreso de los Diputados, serie A, núm. 97-I, de 3 de abril. 
nomía, la contemplación de los Reglamentos municipales y de su proceso de elaboración informa, a la vez, del grado de libertad y de control de la vida municipal y, al contrario, de la misma cuantía de sus competencias, elemento visible en cuanto se examine, siquiera sea someramente, el contenido del articulado de una disposición municipal.

\section{Amplias ReFERENCias a la POTESTAD REglamentaria}

Quizá esta importancia simbólica es todavía más afirmada por el Proyecto por el amplio número de artículos en los que existen referencias a las Ordenanzas y Reglamentos municipales. Prácticamente en la mitad de sus $\mathbf{1 1 5}$ artículos aparecen, de una o de otra forma, las normas locales. Este amplio número de citas es fácilmente comprensible si se tiene en cuenta el verdadero carácter de esta Ley: delimitador, en el fondo, del marco de actuación de determinados Entes: Estado, Comunidades Autónomas, Provincias y Municipios, que se hará efectivo mediante la promulgación de normas por cada uno de ellos. Leyes en el caso del Estado y de las Comunidades Autónomas, Ordenanzas y Reglamentos por las Diputaciones Provinciales y los Ayuntamientos. En cualquier caso, y aun con esta justificación, contrasta la situación con las escasas referencias, por ejemplo, de la Ley de Bases de 1945, por poner el ejemplo de la norma que está en el origen del último «corpus» vigente en el Régimen local español.

\section{LA MODERNIDAD TERMINOLOGGICA}

Hay una modernidad terminológica en el planteamiento de las normas locales: se habla genéricamente de "potestad reglamentaria» (arts. 3 y 101, 2), olvidando viejas e inexactas definiciones doctrinales y reglamentarias, como habían sido la de potestad de ordenanza, poder reglamentario, potestad normativa o facultad legislativa (8).

3. LAS AUTORIDADES QUE PUEDEN EMANAR REglameNTOS MUNICIPALES Y SU FUNDAMENTACIÓN

No obstante esta modernidad reglamentaria, es bien cierto que se mantienen los signos clásicos de la misma, como serían:

(8) Cfr. mi libro Ordenanzas y Reglamentos municipales en el Derecho español, página 611. 
a) Su basamento en el carácter de Administración territorial del Municipio (art. 3) y en la necesidad de intervenir mediante instrumento hábil en la actividad de los ciudadanos (art. 78, 1, a) ).

b) Las autoridades que pueden emanarlas. El Alcalde en los casos de los Bandos (art. 20, 1, e) ), y el Ayuntamiento pleno para los Reglamentos orgánicos y las Ordenanzas (art. 21, 1, d)).

\section{El PROCEDIMIENTO DE ELABORACIÓN}

Mayores cambios existen en el procedimiento de elaboración de las normas locales. De este procedimiento han desaparecido los controles de la Administración del Estado o de las Comunidades Autónomas y que antes adoptaban formas diversas, como autorización, aprobación o advertencia de ilegalidad con suspensión de eficacia. En efecto, el artículo 47 del Proyecto regula de forma general el procedimiento, que constaría de las siguientes fases:

a) Aprobación provisional por el Pleno.

b) Información pública y audiencia a los interesados por plazo mínimo de treinta días para la presentación de reclamaciones y sugerencias. El Proyecto hace referencia a que en esta audiencia actúa el principio del artículo 105, d), de la Constitución.

c) Aprobación definitiva. En este acto se deben resolver las reclamaciones y sugerencias presentadas en plazo.

Podrá existir, es obvio, algún procedimiento que se aparte de alguna forma del aquí reseñado, como podría ser, por ejemplo, el de las normas urbanísticas de los Planes, que seguirán el mismo procedimiento de los Planes. Incluso, y como es elemental, ya en el mismo articulado, y por la omisión producida en el artículo 47, se entiende que no es precisa la información pública para los Reglamentos orgánicos, cuyo carácter interno haría injustificado ese trámite de audiencia.

El procedimiento de elaboración reseñado informa que en el aspecto de aplicación del principio de autonomía, el Proyecto ha ido mucho más allá de lo que estrictamente pedía la sentencia del Tribunal Constitucional de 2 de febrero de 1981. En efecto: han desaparecido de forma general los controles administrativos y es la sola voluntad municipal quien es suficiente para la aprobación de una norma local. Este amplio principio de libertad - no estrictamente 
impuesto por la Constitución y la interpretación que de ella ha hecho el Tribunal Constitucional, pero, por supuesto, no prohibido-, me parece encomiable y debe ser contemplado sin recelos. A lo largo del articulado del Proyecto existen otro tipo de instrumentos de control fundamentalmente basados en la impugnación ante los Tribunales, siendo la garantía de su actuación más que suficiente para asegurarse de la sujeción de las Ordenanzas municipales a la legalidad.

\section{El QUÓRUM DE APROBACIÓN}

La pluralidad de formas reglamentarias posibles tiene sus consecuencias en relación al quórum con que deben ser adoptados los acuerdos de aprobación. Así, aun cuando el principio general es el de la mayoría simple (art. 45,1 ), es preciso el voto favorable de la mayoría absoluta del número legal de miembros de la Corporación para aprobar:

- Los Reglamentos orgánicos (art. 45, 3, a)).

- Las Ordenanzas fiscales (art. 45, 3, h) ).

- Las normas urbanísticas (art. 45, 3, i)).

Esta exigencia de superior quórum es conforme con la tradición de nuestro Derecho y así se encontraba en la LRL.

\section{La PUBLICACIÓN DE LAS ORdENANZAS Y LA ENTRADA EN VIGOR DE SUS PRECEPTOS}

Una importante novedad aporta el Proyecto en cuanto a la publicación de las Ordenanzas. Hacía notar en el capítulo I de este trabajo cómo la falta de exigencia legal de publicación era una ausencia lamentable dentro del régimen de una fuente de Derecho. Pues bien, el artículo 65, 2, del Proyecto corrige este defecto al exigir la publicación en el Boletín Oficial de la Provincia. La entrada en vigor se hace depender de su publicación completa, momento a partir del que comienza a contarse el plazo de quince días, a que se refiere el artículo 60, lapso durante el que la Administración del Estado puede formular requerimientos para que se modifiquen acuerdos municipales o, en nuestro caso, preceptos de las Ordenanzas (9). Pasado, por fin, este plazo, la Ordenanza entra en vigor.

(9) Transcribo el texto del artículo 60 del Proyecto: «1. Cuando la Administración del Estado o de las Comunidades Autónomas considere, en el ámbito de sus 
En el caso de las Ordenanzas fiscales - para las que se predica igualmente la publicación-, la entrada en vigor debe coincidir con la del presupuesto a la que aquéllas acompañan (art. 106).

Una vez que entran en vigor, los Reglamentos municipales obligan al cumplimiento de sus preceptos según un principio territorial (las Ordenanzas fiscales se aplican según los principios de residencia efectiva y territorialidad, dirá el art. 102, 2) y personal, pues las Ordenanzas y Reglamentos son medio hábil para intervenir en la vida de los «ciudadanos» (art. 78, 1, 1), término, obviamente, mucho más amplio que el de vecinos.

\section{Los Lf́mites de los REglamentos mUNICIPALES}

Cuestión batallona tradicionalmente en el régimen de las Ordenanzas y Reglamentos municipales ha sido la de los límites de esta fuente de Derecho. Singularmente, la relación con los Reglamentos estatales ha sido usualmente objeto de un defectuoso tratamiento, que me preocupé en explayar y, en la medida de lo posible, de solucionar en el capítulo VII de mi libro. En el largo y capital artículo 5 del Proyecto se ensaya una pirámide de jerarquía normativa, en la que destaca la referencia legal - sea la Ley del Estado o de las Comunidades Autónomas- a la que se orientan los Reglamentos municipales y, por tanto, la imposibilidad de que Reglamentos independientes del Estado se sobrepongan a las Ordenanzas. Sin ninguna duda de ello va a afectar al régimen de determinadas formas reglamentarias municipales, y en especial a las Ordenanzas sobre actividades industriales, sector en el que el Reglamento de actividades molestas, insalubres, nocivas y peligrosas aparece, veintitrés años después de su emanación, todavía desprovisto del correspondiente apoyo legal (10).

respectivas competencias, que un acto o acuerdo de alguna Entidad local infringe el ordenamiento jurídico, podrá requerirla, invocando expresamente el presente artículo, para que anule dicho acto $o$ acuerdo.

2. El requerimiento deberá ser motivado y expresar las disposiciones que estimen vulneradas. Se formulará en el plazo de quince días hábiles a partir de la recepción de la comunicación de acuerdo.

3. Si la Entidad atendiera el requerimiento en el plazo de quince días hábiles a partir de su notificación, la Administración del Estado o, en su caso, la de la Comunidad Autónoma podrán impugnar el acto o acuerdo directamente ante la jurisdicción contencioso-administrativa».

(10) Vid. la situación en las págs. 582 y sigs. de mi libro. 


\section{LA GENERALIZACIÓN DEL CONTROL JUDICIAL}

Punto capital, y ya anunciado con anterioridad, es el del control sobre la potestad reglamentaria municipal. Se ha abandonado en el Proyecto, como ya se ha dicho, toda idea de control administrativo, y ya el artículo 6, 2, anuncia el control judicial de Ordenanzas, resoluciones y acuerdos. Control judical que el artículo 61, 2, atribuye, como es lógico, a la jurisdicción contencioso-administrativa. Ante esta jurisdicción, y al margen del régimen normal de impugnación de los acuerdos (art. 58), podrá pedirse con el mismo recurso y por la Administración del Estado, la suspensión de la Ordenanza municipal. La fundamentación de esta petición, al contrario de lo que sucede para los actos administrativos singulares, podrá basarse en meros vicios de legalidad y no sólo en exceso de competencia (vid. el artículo 61, 2, en relación con el primer párrafo del 61, 1). El Tribunal decidirá sobre esta petición de suspensión en el primer trámite que tenga lugar tras la impugnación.

Para las Ordenanzas fiscales hay alguna especialidad en el trámite de impugnación. Esta consiste en que la denegación de las reclamaciones que se produzcan en la fase de información pública puede dar lugar a un recurso ante el Tribunal Económico-administrativo provincial. Si en tres meses no ha sido resuelto este recurso, se entiende entonces desestimado, lo que nos sitúa ante la técnica del silencio administrativo negativo. Por fin, es importante resaltar que la interposición de recursos no puede suspender nunca por sí sola la aplicación provisional de Ordenanzas fiscales.

\section{FINAL: LA NUEVA ORDENACIÓN DE LAS COMPETENCIAS MUNICIPALES}

Las Ordenanzas municipales como símbolo, decía, no sólo de la libertad de elaboración, sino del mismo contenido de la competencia municipal material. El nuevo Régimen local debe estructurarse con arreglo a criterios bien distintos de reparto de competencias que los que tenían lugar en el sistema de la LRL. El principio genérico de autonomía de la Constitución así lo pide, y el proceso de transferencia de competencias a las Comunidades Autónomas no debe hacerse a costa de sustraer o de olvidar los legítimos derechos de las Corporaciones locales. Debe encontrarse, en cada caso, al Ente territorial idóneo para ejercitar una actuación, y de ahí la referencia en muchos Estatutos de Autonomía a la posibilidad de que las Co- 
munidades Autónomas deleguen competencias a las Provincias, y en solo un caso expresamente a los Municipios (11). Estamos y entramos, por tanto, en un período de redefinición de competencias, que deberá hacerse siguiendo el dictado constitucional de autonomía y su plasmación en cada caso concreto. Conviene advertir, por último, que el Proyecto, haciéndose eco del moderno concepto de autonomía municipal elaborado por la doctrina alemana, y singularmente por BURMEISTER (12), e incorporado a la doctrina de nuestro país por EMBID y PAREJo (13), contiene un artículo, como el 2, 1, claramente representativo de la nueva orientación, y que transcribo como punto final de esta breve reflexión en torno a la potestad reglamentaria municipal:

«Para la efectividad de la autonomía garantizada a la Administración local, la legislación del Estado y la de las Comunidades Autónomas, reguladora de los distintos sectores de acción pública según la distribución constitucional de competencias, deberá asegurar a los Municipios, las Provincias y las Islas su derecho a intervenir en cuantos asuntos afecten directamente al círculo de sus intereses, atribuyéndoles las competencias que proceda en atención a las características de la actividad pública de que se trate y a la capacidad de gestión de la Corporación local, de conformidad con los principios de descentralización y de máxima proximidad de la gestión administrativa a los ciudadanos».

(11) Es el supuesto que contempla el artículo 45, 3, del Estatuto de Autonomía de Aragón, y que transcribo a continuación: «La Comunidad Autónoma podrá transferir o delegar en las Diputaciones y en los Ayuntamientos, mediante Ley aprobada por mayoría absoluta, facultades correspondientes a materias de su competencia. Esta Ley preverá en cada caso la correspondiente transferencia de medios financieros, así como la forma de dirección y control que se reserve la Comunidad».

Sobre el mismo remito a las págs. 178 y sigs. de mi libro: El marco jurídico de la autonomía. Estudios sobre el Estatuto de Autonomía de Aragón, Ed. Ayuntamiento de Zaragoza, Zaragoza, 1983.

(12) La obra de J. BURMrister lleva como título Verfassungstheoretische Neukonzeption der Kommunalen selbstverwaltungsgarantie, Verlag Vahlen, München, 1977, XXXIV + 201 págs.

(13) Vid. mi trabajo citado en nota 3 y el libro de L. Parejo: Garantía institucional y autonomias locales, Ed. IEAL, Madrid, 1981. 